\title{
THE LYSIS OF ARTIFICIALLY INDUCED INTRAVASCULAR CLOTS IN MAN BY INTRAVENOUS INFUSIONS OF STREPTOKINASE * $\dagger$
}

\author{
By ALAN J. JOHNSON AND W. ROSS MCCARTY \\ (From the Departments of Medicine and Surgery, New York University College of Medicine, \\ and the Third Medical and Surgical Divisions of Bellevue Hospital, \\ New York, N. Y.)
}

(Submitted for publication August 18, 1958; accepted June 1, 1959)

Streptokinase has been shown to be an effective therapeutic agent, effecting the rapid lysis of extravascular fibrin clots in man (1). As a result, extensive clinical studies of extravascular clot lysis have been made in a variety of disease states $(2,3)$. In the present studies, streptokinase was found to be equally effective in the lysis of artificially induced intravascular clots in man, when administered intravenously under precisely controlled biochemical conditions.

Recent investigations have indicated that streptokinase reacts with a proenzyme in plasminogen to form an activator complex (4-6). This complex, designated "activator" reacts with plasminogen (the proteolytic precursor) to form a proteolytic enzyme, plasmin $(7,8)$. In order to be effective in man, this proteolytic system must be uninhibited, or "free." The system may be interfered with at three levels. Streptokinase may be neutralized by its specific antibody and, therefore, be unavailable for activating the system; "activator" may be neutralized by inhibitor found in the plasma; and plasmin may react with still another inhibitor in the plasma (9-12).

Previous clinical studies of intravascular fibrin clot lysis for the therapy of thromboembolic disease in man have utilized streptokinase to activate the patient's plasminogen in vivo, or purified plasminogen previously activated in vitro (13-16). Interpretations of these earlier clinical studies are complicated by variations in the natural course of disease and by an anti-inflammatory effect which

\footnotetext{
* This study was presented in part at the annual meeting of the Surgical Forum of the American College of Surgeons, Chicago, Illinois, October 8, 1958.

$\dagger$ This study was supported by research grants from the National Heart Institute (No. H-55, C11) of the Department of Health, Education and Welfare, United States Public Health Service; and Lederle Laboratory Division, American Cyanamid Company, Pearl River, N. Y.
}

may follow clinical use of the enzymes $(13,17$, 18).

In the present investigation, reproducible data were obtained by inducing experimental thrombi in human volunteers by direct irritation of the intima with a dental broach or by chemical irritation with sodium morrhuate. The position and size of the thrombi were determined by clinical observation and by venograms. The proteolytic system in blood believed to be responsible for physiological clot lysis (plasmin) was then activated by infusing streptokinase (SK) into a contralateral extremity at varying time intervals after clot formation.

Three different systems were established by varying the amount of SK infused:1) moderate amounts of circulating plasmin with no measurable free SK $(\operatorname{Method} P) ; 2)$ negligible plasmin with moderate amounts of free SK or activator $($ Method $S K)$; 3) small amounts of both free SK and plasmin (Method SK-P). Since preliminary experiments had indicated that clot lysis was frequently followed by reformation of the clot at the same site, each system was evaluated for both its ability to lyse the experimental thrombi and prevent reformation of the thrombi.

In order to produce a fibrinolytic system by any of the three systems, it was found to be necessary to give an initial, or priming dose, sufficient to just neutralize the circulating SK antibody and inhibitor in each patient. Additional infused SK was then free to produce active proteolysis. This additional SK was infused in a first sustaining dose, in an amount appropriate for the production of one of the three proteolytic systems enumerated above, and these conditions were maintained in vivo for 24 to 36 hours by the continuous infusion of a second sustaining dose of SK. When thrombolysis had occurred, reformation of the clot was 


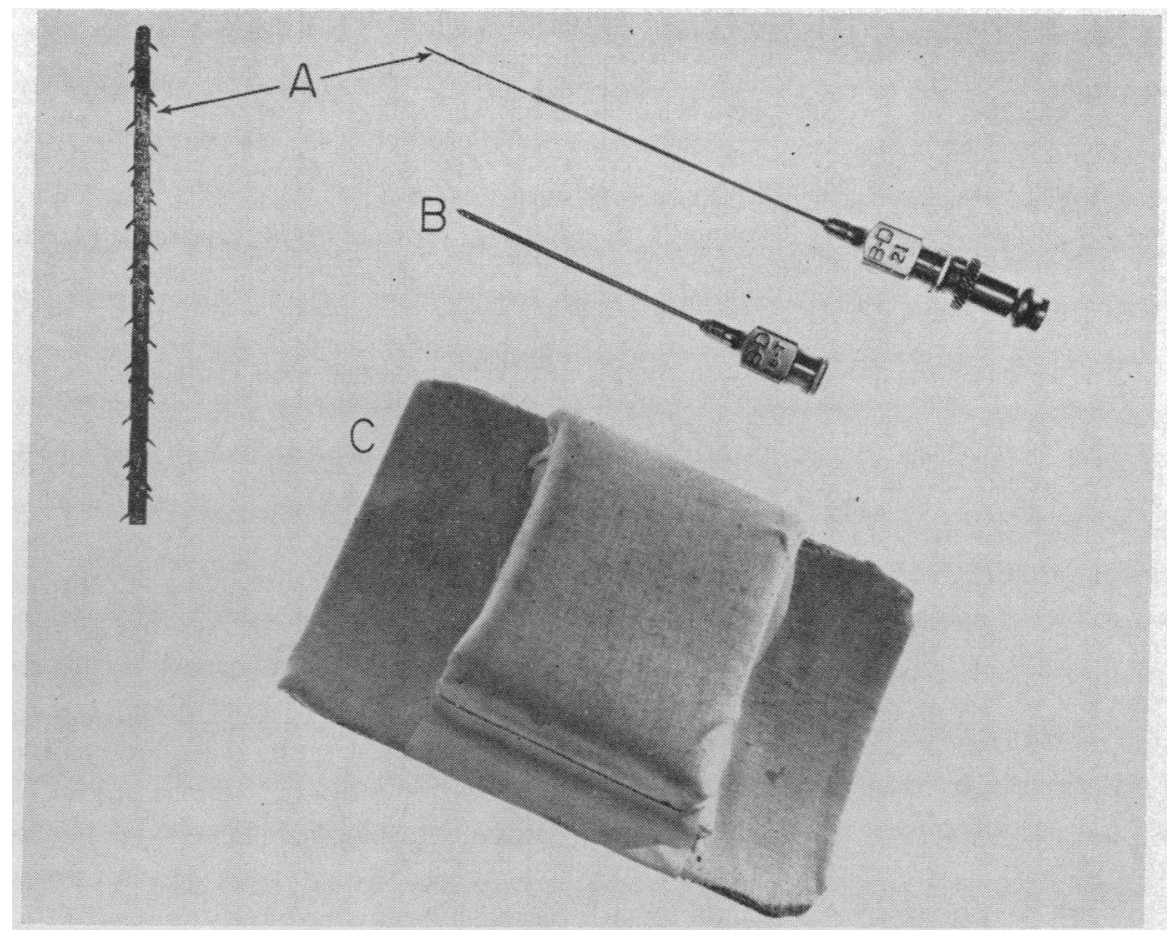

Fig. 1. Apparatus for Induction of Blood Clots in Peripheral Veins

A) Dental broach soldered in tip of two inch, No. 21 needle and photomicrograph of dental broach showing blunt tip and barbed area. B) Thin-wall No. 18 needle for venotomy and introduction of dental broach. C) Sponge rubber pad backed with stainless steel, for local application of pressure on proximal portion of vein.

prevented in those patients with sufficient residual plasminogen by prolonging the SK infusion for an additional four to six hours.

The amount and duration of the SK infusions necessary were determined primarily by following the various biochemical components of the streptococcal fibrinolytic system in the patient's blood before, during and after the infusions. By this means, it was possible to establish minute to minute control of the proteolytic conditions, making frequent changes of the infusion rate to maintain an appropriate balance of plasmin, plasminogen, plasmin-activator, SK and prothrombin. A balance was found to be necessary to lyse intravascular clots consistently and reproducibly and to prevent reformation of the clots.

A further check was provided by determining the presence or absence of the clot at frequent intervals by inspection, palpation and $\mathrm{X}$-ray venograms of the affected extremity.

\section{MATERIALS AND METHODS}

Induction of standard thrombus. The blunt tip of a coarse dental broach ${ }^{1}$ was soldered in the end of a two inch No. 21 needle ${ }^{2}$ after the point had been cut off at right angles to the needle shaft (Figure 1). The broach was introduced into the lumen of the vein through a thin-walled No. 18 needle $^{3}$ and the shaft of the No. 21 needle rotated to the right and left through $360^{\circ}$ for five minutes. At the same time, the No. 18 needle was moved back and forth on a longitudinal axis to the vein and digital pressure was applied to the vein wall overlying the dental broach. These measures served to insure irritation of the intima over the entire area.

Immediately after the needle was removed, local pressure was applied and a foam rubber pad (Figure 1)

1 Dental Broaches, No. 6, extra coarse; Charles B. Schwed Company, New York, N. Y.

2 Hypodermic needle, 21 gauge, two inch length; Becton, Dickinson and Company, Rutherford, N. J.

${ }^{3}$ Hypodermic needle, 18 gauge, thin wall, one and onehalf inch; Becton, Dickinson and Company, Rutherford, N. J. 
was loosely bound (with an elastic bandage ${ }^{4}$ ) proximal to the affected portion of the vessel for 18 to 24 hours to slow the rate of flow, fix the clot and prevent embolization.

A firm occluding clot was formed in less than 15 minutes. Blood clots 5 to $20 \mathrm{~cm}$. long were produced by this method in the superficial saphenous veins or the veins of the forearm. A few clots were produced by means of a sclerosing agent, sodium morrhuate. ${ }^{5}$ The technique was an adaptation of one previously used (19) and was found to be too complicated for use in man.

The presence or absence of the clot was determined by inspection, palpation and X-ray venograms taken before, during and after the SK infusion. Repeated venograms were made with diatrizoate sodium ${ }^{6}$ diluted to 13 per cent in saline to prevent irritation of the intima. At least two $\mathrm{X}$-rays were taken for each venogram. One view was made with a retrograde pressure of $40 \mathrm{~mm}$. of mercury proximal to the clot and the other was made without retrograde pressure. In both instances, a standard pressure of $110 \mathrm{~cm}$. of water was used to inject the diatrizoate sodium.

Streptokinase. Lots $21 \mathrm{~A}, 22 \mathrm{~A}$ and $23 \mathrm{~A}$ of concentrated, highly purified streptokinase (SK) were used. ${ }^{7}$ Each contained approximately 600 units of SK per $\mu \mathrm{g}$. of nitrogen and was virtually free of streptococcal desoxyribonuclease.

Preparation and rate of infusions. Streptokinase for intravenous use was dissolved in a solution containing 5 per cent dextrose and one-half per cent human serum albumin. ${ }^{8}$ As a priming dose, 1 to $2 \mathrm{ml}$. of a solution containing 5,000 units per $\mathrm{ml}$. was infused each minute until 100,000 to $1,000,000$ units was administered. As a sustaining dose, $2 \mathrm{ml}$. of a solution containing 240 to 320 units per $\mathrm{ml}$. (depending on the method used) was infused per minute for approximately 24 hours. Since the infusion rate was very critical, specific variation from this will be considered in individual protocols.

Clinical observations. During the period of the infusion, pulse, temperature and blood pressure were taken every hour or when specifically indicated, every $15 \mathrm{~min}$ utes. The thrombosed vessel was examined hourly by at least two observers. After the infusion, the observations were generally continued for 24 to 48 hours.

Anti-pyretic medication. If a temperature elevation to $102^{\circ} \mathrm{F}$. or more occurred, four doses of amidopyrine $\left(0.6 \mathrm{Gm}\right.$.) and chlorprophenpyramine maleate ${ }^{9}(4 \mathrm{mg}$.)

${ }^{4}$ Ace Bandage ${ }^{\circledR}$; Connecticut Bandage Mills, Inc., Bridgeport, Conn.

5 Sodium morrhuate 5 per cent with benzyl alcohol 2 per cent; G. D. Searle and Company, Chicago, Ill.

${ }^{6}$ Hypaque ${ }^{\circledR}$ brand of diatrizoate sodium, Winthrop Laboratories, New York, N. Y.

'The highly purified streptokinase was supplied by Lederle Laboratories Division, American Cyanamid Company, Pearl River, N. Y.

8 Normal serum albumin (human), salt-poor, U.S.P., Cutter Laboratories, Berkeley, Calif.

${ }^{9}$ Chlor-Trimeton Maleate ${ }^{\circledR}$ brand of chlorprophenpyramine maleate, Schering Corporation, Bloomfield, N. J. were given during the subsequent 24 hour period as indicated previously (20).

\section{ANALYTICAL METHODS}

In order to compare fibrinolytic or inhibitor activities, each unit was based upon the amount required to lyse a standard clot in 10 minutes, except for plasminogen, which was 30 minutes. Thus, these activities were interconvertible.

Streptokinase. The fibrinolytic assay for streptokinase was performed by a modification of the method of Christensen (21) as previously described (19).

Streptokinase-activated plasmin. Logarithmic dilutions of plasma were added to the standard clot system used above (19) except that a lot of bovine fibrinogen 10 was used which was found to be low in contaminating plasminogen and was further purified by the method of Laki (22).

A modification of the method of Schwert and Takenaka (23) was also employed for the quantitative determination of plasmin, utilizing a final concentration of $0.002 \mathrm{M}$ benzoylargenine methyl ester.

A qualitative fibrinolytic test for SK-plasmin was also performed by the addition of fresh undiluted whole blood to a previously siliconed ${ }^{11}$ graduated centrifuge tube fitted with a wire retainer for the formed clot. The "per cent lysis" as described previously (20) was easily obtained by this method. When the "per cent lysis" was less than 25 per cent, it was arbitrarily considered to be due to clot retraction. With one exception, in this laboratory, the "per cent lysis" (or clot retraction) of normal controls has been less than 20 per cent in more than a thousand determinations.

$S K$-activator complex and/or free $S K$. Dilutions of patient plasma were added to an excess of plasminogen and tested as in the SK assay. The fibrinolytic activity of the contained plasmin (as determined separately) was subtracted from the total, the remainder representing activator and/or free SK. Since the assay did not distinguish between activator and free SK, they will not be differentiated further in this study.

Streptokinase antibody and SK-plasmin inhibitor. Because the measurement of SK antibody and SK-plasmin inhibitor presented a number of special problems, biochemical and immunologic studies on them will be presented in detail in a subsequent publication. The SKplasmin inhibitor under consideration here was found to be comparable with the fast-acting alpha- 2 inhibitor of Jacobsson (10) and Norman and Hill (11). Measurements of antiplasmin were also made, but were not reported here since they did not appreciably influence the amount of proteolysis induced during the infusion of SK.

Each unit of antibody and inhibitor represents the inhibition of one unit of SK in the standard SK assay. Since the inhibition reaction was not temperature-dependent, preincubation of the test substance with SK was

${ }^{10}$ Bovine Fibrinogen, lot No. N1803, The Armour Laboratory, Kankakee, Ill.

${ }_{11}$ DC 200, Dow-Corning Corporation, Midland, Mich. 
TABLE I

Streptokinase antibody and SK-plasmin inhibitor in the circulating blood of patients prior to the intravenous infusion of $S K$

\begin{tabular}{|c|c|c|c|}
\hline Patient & Antibody & Inhibitor & $\begin{array}{c}\text { Total inhibition } \\
\text { (antibody and inhibitor) }\end{array}$ \\
\hline Cra & 40,250 & 43,050 & 83,300 \\
\hline $\mathrm{Pab}$ & 52,700 & 61,000 & 114,000 \\
\hline Dav & 63,000 & 79,000 & 142,000 \\
\hline O'To & 58,000 & 89,000 & 147,000 \\
\hline Moo & 85,000 & 145,350 & 230,850 \\
\hline $\mathrm{Nic}$ & & & 290,000 \\
\hline Jon & 153,000 & 147,000 & 300,000 \\
\hline $\mathrm{McD}$ & 132,000 & 189,000 & 321,000 \\
\hline Gle & 173,000 & 177,000 & 350,000 \\
\hline $\mathrm{Jac}$ & 202,000 & 248,000 & 450,000 \\
\hline Bor & 225,000 & 245,000 & 470,000 \\
\hline Tur & 470,000 & 70,000 & 540,000 \\
\hline Bla & 160,000 & 410,000 & 570,000 \\
\hline Sve & 340,000 & 245,000 & 585,000 \\
\hline Mus & 380,250 & 302,250 & 682,500 \\
\hline Total $=15$ & $\begin{array}{l}\text { Mean } 194,977 \\
\text { Range } 40,250-470,000\end{array}$ & $\begin{array}{l}\text { Mean } 175,046 \\
\text { Range } 43,050-410,000\end{array}$ & $\begin{array}{l}\text { Mean } 354,670 \\
\text { Range } 83,300-682,500\end{array}$ \\
\hline
\end{tabular}

carried out for 10 minutes at $4^{\circ} \mathrm{C}$. in order to minimize the activation of contaminating plasminogen. In practice, the inhibition of one-half of a unit was determined and the value then doubled. At least 10 tubes were used for each assay with six dilutions and a one unit and two one-half unit controls. A means of separating antibody from inhibitor activity was developed when it was found that strong chelating agents such as disodium ethylenediamine tetraacetate ${ }^{12}$ or an ion exchange resin ${ }^{13}$ removed SK-plasmin inhibitor activity but had no effect upon the SK antibody. Both activities are present in serum. Therefore, the SK-plasmin inhibitor was estimated by subtracting the antibody value found in plasma from the total inhibition in the serum.

The inhibitor and antibody obtained by these methods were calculated per $\mathrm{ml}$. of plasma. These values, in turn, were multiplied by the estimated plasma volume to determine the total circulating antibody and inhibitor for each patient.

Plasminogen. The fibrinolytic assay for plasminogen was performed as described previously (19).

Fibrinogen. Blömback and Blömback's (24) method was employed. The isolation procedure was performed with ice cold reagents, in an ice bath. Considerable emphasis was placed on clot formation at an optimal concentration of fibrinogen. The optical density at 282 $\mathrm{m} \mu, \mathrm{E}_{1}^{1} \mathrm{~cm}$. cent, was found to be approximately 16.17 for fibrinogen in alkaline urea solution as previously determined by Blömback.

Complement. The serum complement was determined by the method employed by Fischel, Pauli and Lesh (25).

Prothrombin. A one-stage determination was utilized

12 Versene ${ }^{\circledR}$ brand of disodium ethylenediamine tetraacetate, Versenes, Inc., Framington, Mass.

13 Dowex 50-X®, Dow Chemical Corporation, Midland, Mich. for the prothrombin time with each of the two thromboplastins ${ }^{14}$ used. The second is stated to be free of proconvertin-like activity (26).

\section{RESULTS}

\section{A. Biochemical rationale}

Phase I. Neutralization of antibody and inhibitor. In previous reports $(20,27)$, it was concluded that circulating SK antibody and SKplasmin inhibitor(s) must be neutralized by the injection of at least an equivalent amount of SK to establish a fibrinolytic system in vivo. Further studies seemed to indicate that the fast acting inhibitor of Jacobsson (10) was primarily responsible for inhibition of the activation of SKplasmin in vivo. Therefore, antibody and inhibitor determinations were made on both the patient's plasma and serum prior to the infusion of SK.

The amounts of antibody and inhibitor found in most of the patients included in this study are tabulated in Table I. Those samples tested by a less accurate method developed earlier are omitted. The mean antibody level was 194,977 units and the range was 40,250 to 470,000 units. The mean inhibitor level was 175,046 units and the range was 43,050 to 410,000 units. It is evident that the range of each of these was very wide indeed

14 Simplastin $\AA$, Warner-Chilcott Laboratories, Morris Plains, N. J. and Acuplastin brand of thromboplastin extract, OrthoPharmaceutical Corporation, Raritan, N. J. 
and prior determination of these values is essential for the estimation of an appropriate priming dose of SK to neutralize the antibody and inhibitor in vivo.

Strong evidence was obtained that the priming dose necessary to produce detectable fibrinolytic activity could be based upon the total inhibition present in the blood. The infusion of an amount of SK equal to the SK antibody in the plasma produced no detectable fall in the circulating plasminogen. An amount of SK equal to, or just greater than, the combined antibody and SK-plasmin inhibitor (100 per cent on the abscissa, Figure 2) produced a barely detectable change in the circulating plasminogen. The results were the same in patients treated to produce an excess of plasmin (Method $P$ ) or free SK (Method SK). Direct measurements showed that little or no plasmin was formed during Phase I and neutralization was virtually complete. These plasmin measurements were corroborated by studies of the lysis time of the patients' whole blood when clotted in vitro as for a Lee-White clotting time, by one-stage prothrombin-time determinations (Figure 3 ) in which the destruction of accelerator globulin or prothrombin occurs in the presence of free plasmin $(20,28,29)$ and by measurement of the fibrinogen and complement levels of the plasma $(20,30)$. The extent and mode of participation of antibody and inhibitor, respectively, in this neutralization, are not clear.

In a few instances where the infusion rate for the priming dose was very rapid, the resulting high concentration of SK produced an increase in the velocity of the enzyme-substrate reaction and therefore a fall in plasminogen which was relatively independent of the antibody titers in the peripheral blood. This sequence of events is illustrated in Table II, when 572,000 units of SK was given within a period of one hour and 12 minutes.

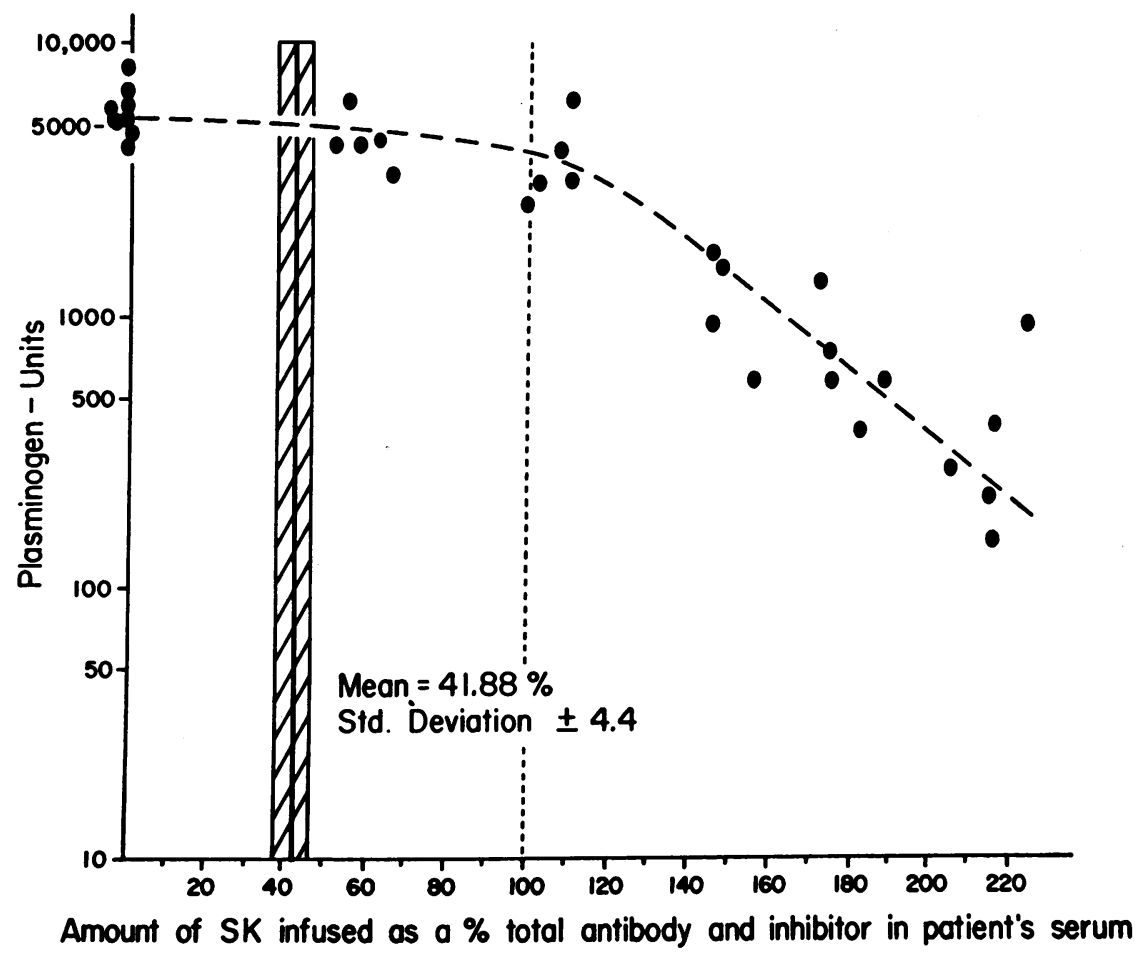

Fig. 2. Effect of Intravenous Infusion of Priming and First Sustaining Dose of Streptokinase on Plasminogen Levels of Patients Treated According to METhod SK-P (Semi-Log Plot)

Dashed line represents a mean of values. At cross-hatched line, 41.88 per cent, amount of SK infused is equal to mean of total antibody in patient's serum; at dotted line, 100 per cent, amount of SK infused is equal to total antibody plus inhibitor in patient's serum. 


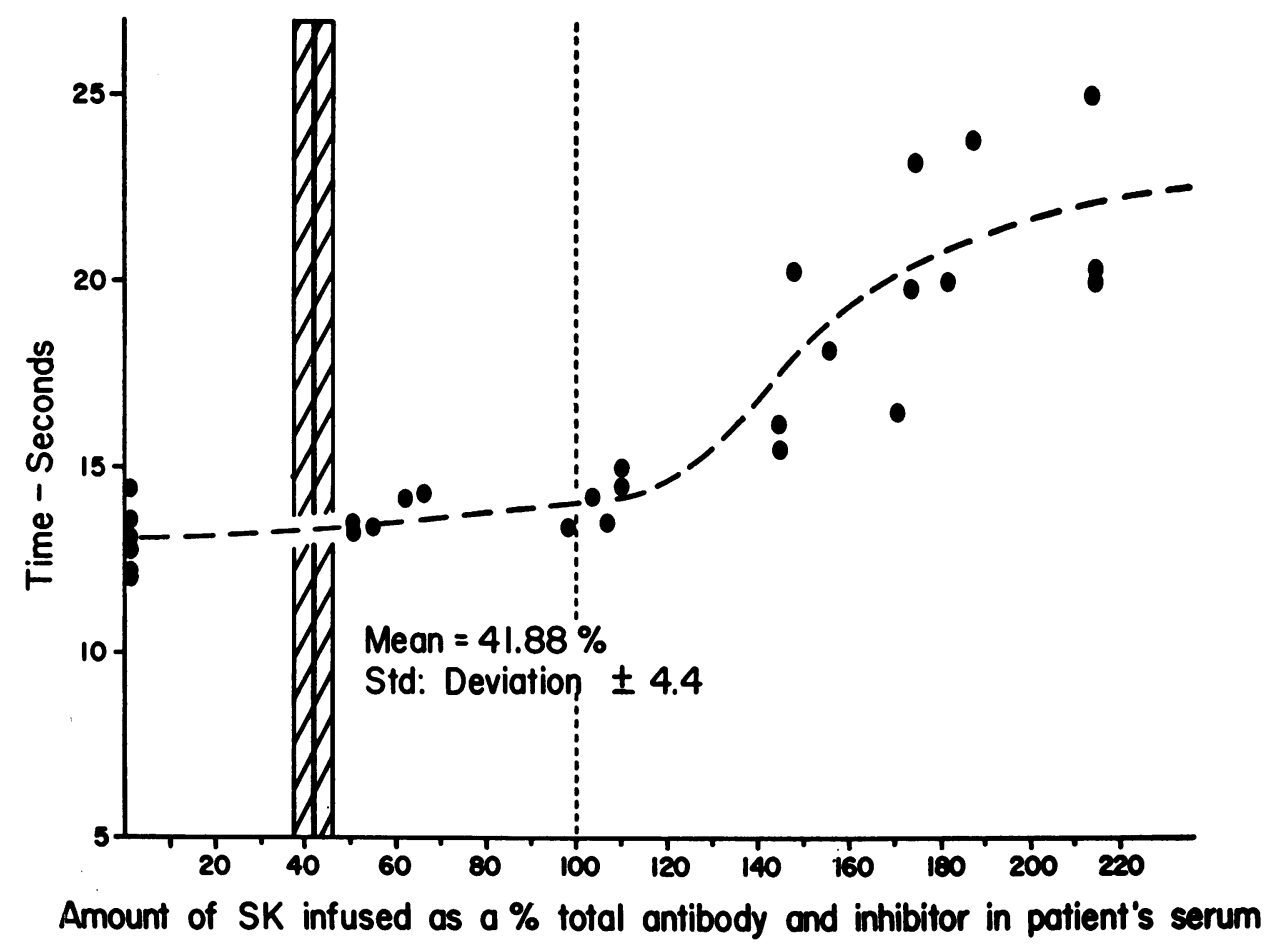

Fig. 3. Effect of Intravenous Infusion of Priming and First Sustaining Doses of Streptokinase on the Prothrombin time, as Determined on Plasma of Patients Treated ACCORDING to METHOD SK-P

Dashed line represents a mean of values. At cross-hatched line, 41.88 per cent, amount of SK infused is equal to mean of total antibody in patient's serum; at dotted line, 100 per cent, amount of SK infused is equal to total antibody plus inhibitor in patient's serum.

Rarely, during a moderately rapid infusion of the priming dose $(20,000$ to 30,000 units per minute), the plasminogen, antibody and inhibitor fell slowly concurrently, during the entire period of Phase I. When the infusion rate was very slow (less than 500 units per minute), SK antibody fell first, then inhibitor and finally, plasminogen. These data were attributed to differences in the rate of association of SK and antibody, activator and inhibitor and activator and plasminogen.

Phase II. Initiating a fibrinolytic system. Following neutralization of the antibody and inhibitor, additional SK was infused as a first sustaining dose, in an amount appropriate for the production of each of the three proteolytic systems.

Small amounts of SK (about 5,000 units per

TABLE II

Effect of the intravenous infusion of the priming dose of streptokinase on the circulating antibody, inhibitor and plasminogen levels in a patient

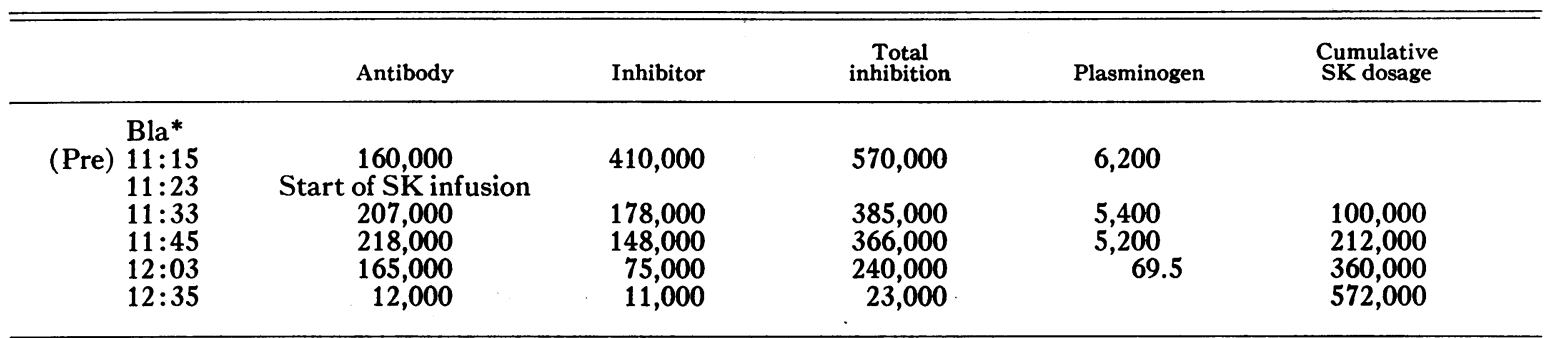

* Patient Bla was infused rapidly at the rate of 10,000 units per minute. 
hour) produced moderate or large amounts of plasmin (Method $P$ ). The plasminogen level was only moderately reduced by this procedure from 5,000 units to 2,000 or 3,000 units per $\mathrm{ml}$. of plasma.

Large amounts of SK $(200,000$ to 400,000 units per hour) produced a very rapid fall in plasminogen to levels of less than 100 units, and free SK or activator was evident in the blood (Method $S K$ ). No free plasmin could be detected.

With intermediate amounts of SK (about 100,000 units per hour for two to three hours) the plasminogen fell rapidly to levels of 200 to 500 units (Figure 2) and small amounts of plasmin and free SK were released into the circulation (Method SK-P).

Phase III. Sustaining the fibrinolytic system. SK was infused for periods up to 48 hours in Phase III to sustain the fibrinolytic system according to one of the three methods outlined below. In those patients treated according to Method $P$, Phase II merged imperceptibly with Phase III. Thus, the injection of very small amounts of SK (25,000 to 50,000 units per day) produced moderate levels of plasmin in the circulating blood for as long as three to five days. As a result, lysis of the patient's clotted whole blood was effected in vitro within two to three hours, the one-stage prothrombin time was markedly elevated, and the fibrinogen was moderately or markedly depleted with potentially serious effects to the patient. In two patients, the prothrombin time went up to 50 seconds, the fibrinogen was no longer detectable and a few small areas of petechiae and ecchymosis appeared on the skin.

In patients treated by Method SK, free SK was maintained in the circulating blood for long periods of time by a sustained, continuous infusion of 45,000 to 60,000 units per hour. Since the patient's plasminogen was already low, this excess SK drove the level down further to less than 100 units per $\mathrm{ml}$. of plasma. When rapidly induced, little free plasmin was produced by this method, the coagulation constituents were not markedly depleted and the prothrombin time rarely rose to more than 23 to 24 seconds.

In Method $S K-P$, an attempt was made to generate small amounts of both $\mathrm{SK}$ and plasmin in the circulating blood. The infusion rate ranged from 20,000 to 45,000 units per hour, varying from 30,000 to 45,000 units per hour in high antibody, high inhibitor patients to 20,000 to 30,000 units in low antibody, low inhibitor patients.

The rate of infusion, to provide free SK without excessive depletion of the endogenous plasminogen, was very critical. This was necessary to provide sufficient enzyme for the lysis of the secondary clots which tended to reform on the matrix of the original clot. In practice, when the plasminogen level was maintained at approximately 100 to 200 units per ml. of plasma, clot lysis generally occurred without clot reformation. At plasminogen levels below 100 units per ml., the initial clot generally lysed but tended to reform. At plasminogen levels above 300 units per ml. the initial clot was markedly resistant to lysis. Therefore, an effort was made to maintain the plasminogen level at approximately 100 to 200 units until the clot was lysed (Figure 4).

The infusion rate during Phase III varied for each patient, and in addition, had to be changed during the infusion period. In general, a steady state was maintained for only eight to 10 hours when the plasminogen level began to go down very slowly. This could be compensated for by decreasing the rate of infusion by about 2,500 units of SK per hour, at appropriate time intervals.

The importance of this decrease in plasminogen was brought to our attention on several occasions by palpable evidence of clot reformation concurrent with a temporary, minor fall in plasminogen (below 100 units). The clot which reformed usually lysed again when the SK infusion was immediately decreased by as little as 2,500 to 5,000 units per hour. It is significant, however, that when clot reformation followed a sustained reduction in plasminogen, the absence of adsorbed plasminogen on the fibrin clot made it almost impregnable to further treatment.

Although the plasminogen assay is extremely sensitive, has a very wide range and indicates activator activity of plasminogen, it became increasingly evident that it was not sufficiently sensitive to be used as the only guide to the infusion rate in the fine balance of enzyme and substrate necessary in this phase.

Plasmin and free SK assays were also used in an attempt at a more precise regulation of the infusion rate. However, the difficulties indicated in Materials and Methods limited their usefulness. 


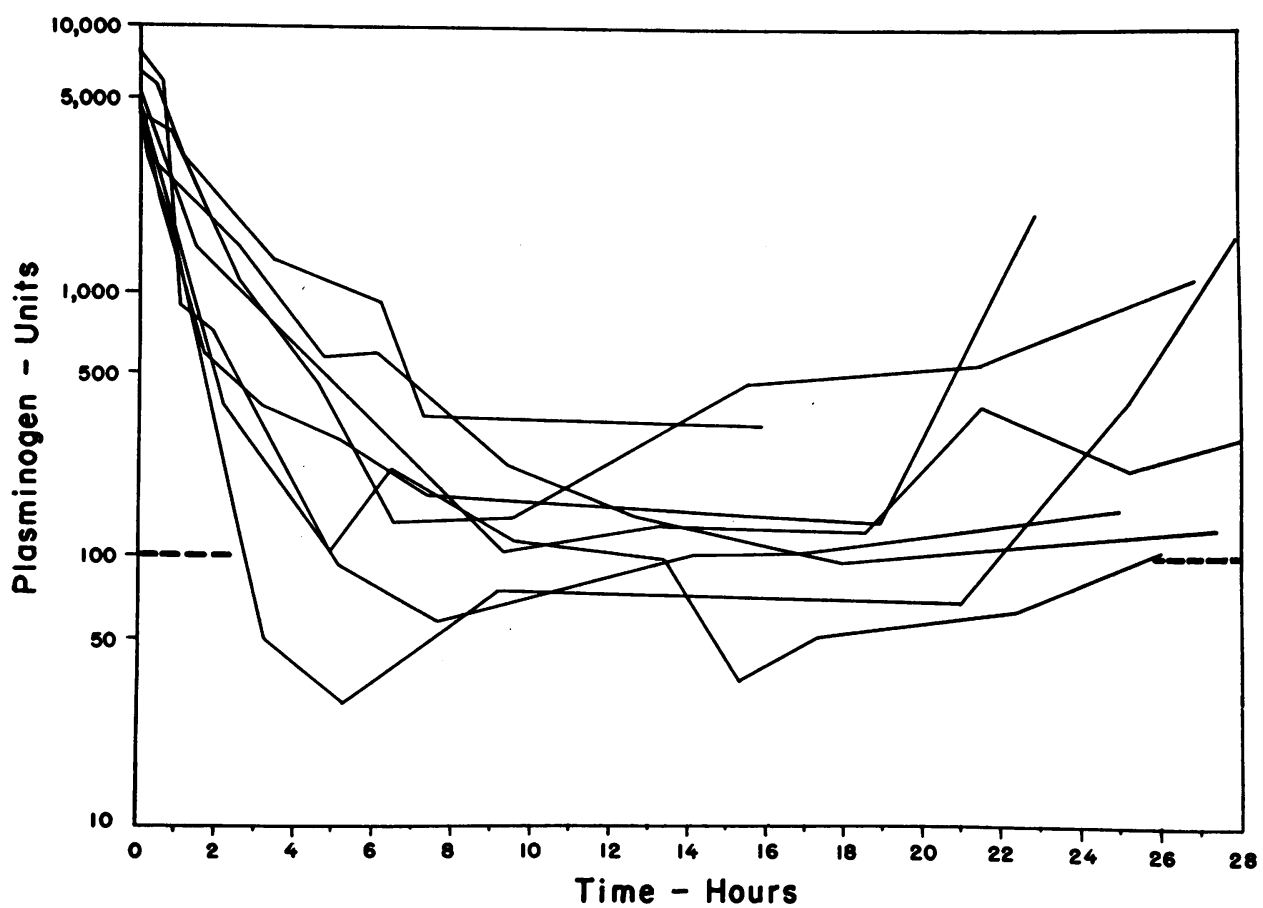

Fig. 4. Effect of Intravenous Infusion of Streptokinase on Plasminogen Levels of Patients Treated According to Method SK-P

For emphasis, an abscissa was drawn through 100 units of plasminogen on the ordinate.

The one-stage prothrombin test has been mentioned as an indicator of plasmin activity in Phases I and II. When the test is performed by one individual, a variation of only two seconds in a sequential test may become an important, early guide toward a change in the infusion rate. After a steady state has been reached, a two second increase in the prothrombin time may denote excess plasmin formation, while a comparable decrease may indicate excess activator or SK in the circulating blood.

When a clot had been lysed, the infusion rate became much less critical. There was very little "need" for free SK, and the SK infusion rate was decreased very gradually to allow the plasminogen to increase to 200 or more units (Figure 4). The infusion was continued at this rate for four to six hours longer to minimize the danger of excessive plasminogen depletion with clot reformation and to provide more plasmin for the lysis of secondary clots.

Illustrative case: Method SK-P. The dynamic interaction of the components of the fibrinolytic system may be seen in data from Patient BOR, given 2,145,000 units of SK according to Method
$S K-P$, over a period of 31 hours (Figure 5). His circulating blood was estimated to contain approximately 225,000 units of antibody and 245,000 units of inhibitor, a total of 470,000 units of inhibition.

Two blood clots were induced in Patient BOR by the dental broach technique. A clot $10.5 \mathrm{~cm}$. long formed in the forearm veins of the left arm 48 hours prior to the infusion. A clot 15 $\mathrm{cm}$. long formed in the forearm veins of the right arm 24 hours prior to the infusion of SK. The position and size of the clots were documented by venograms.

In Phase I, a priming dose of 500,000 units of SK was infused over a 25 minute period. As a result, the plasminogen, complement and fibrinogen levels decreased slightly. When the patient's whole blood was allowed to clot in vitro, about 75 per cent lysis occurred in 24 hours, although no lysis was evident in eight hours. The prothrombin time was normal and the plasmin and free SK assays were negative. It would appear that neutralization of the antibody and inhibitor was barely complete at the end of the priming 
dose, a marginal amount of plasmin was produced, and the streptococcal fibrinolytic system was ready for activation.

In Phase II, 150,000, 100,000 and 75,000 units of SK were injected rapidly as "stat" injections during a continuous infusion of 32,000 units per hour. The plasminogen level promptly decreased from 6,000 units to about 100 units, five to six units of plasmin and one unit of free SK appeared; the prothrombin time rose from 14 to 20 seconds and the patient's per cent lysis increased to 100 per cent in two hours. Thus, an effective fibrinolytic system was produced during Phase II, with a demonstrable amount of free SK and plasmin.

In this patient, and indeed, in most of the patients treated according to Methods $S K-P$ and $S K$, the fibrinogen and complement levels remained about the same during this phase. This was interpreted to mean that plasmin was destroyed almost as quickly as it was formed, and being present only transiently, affected only the preferential substrates, plasminogen, accelerator globulin and prothrombin. Rapid administration of moderate amounts of SK was essential for this prompt elimination and control of the formed plasmin. In other patients, when SK was given too slowly during Phase II, plasmin was not rapidly destroyed and fibrinogen, complement and prothrombin were seriously depleted.

In Phase III, the infusion rate was increased to 40,000 units per hour for about five hours. During this period the 24 hour clot softened perceptibly, decreasing from $15 \mathrm{~cm}$. in length to about $5 \mathrm{~cm}$. The infusion rate was then arbitrarily increased to 50,000 units per hour in an attempt to reverse the lytic process. Shortly after the fifteenth hour, the plasminogen level dropped to 50 units and the clot reformed (at arrow, Figure 5). The infusion rate was promptly decreased to 45,000 units, then to 40,000 units, when thrombolysis started again. This type of experiment was performed repeatedly. As indicated previously, when the infusion rate was not decreased immediately, the clot resisted all further efforts to lyse it.

About 24 hours after the start of the infusion, when the clots were thought to be lysed, the infusion rate was decreased to 35,000 units per hour and maintained at that level for approximately six additional hours. It may be noted that the plas-

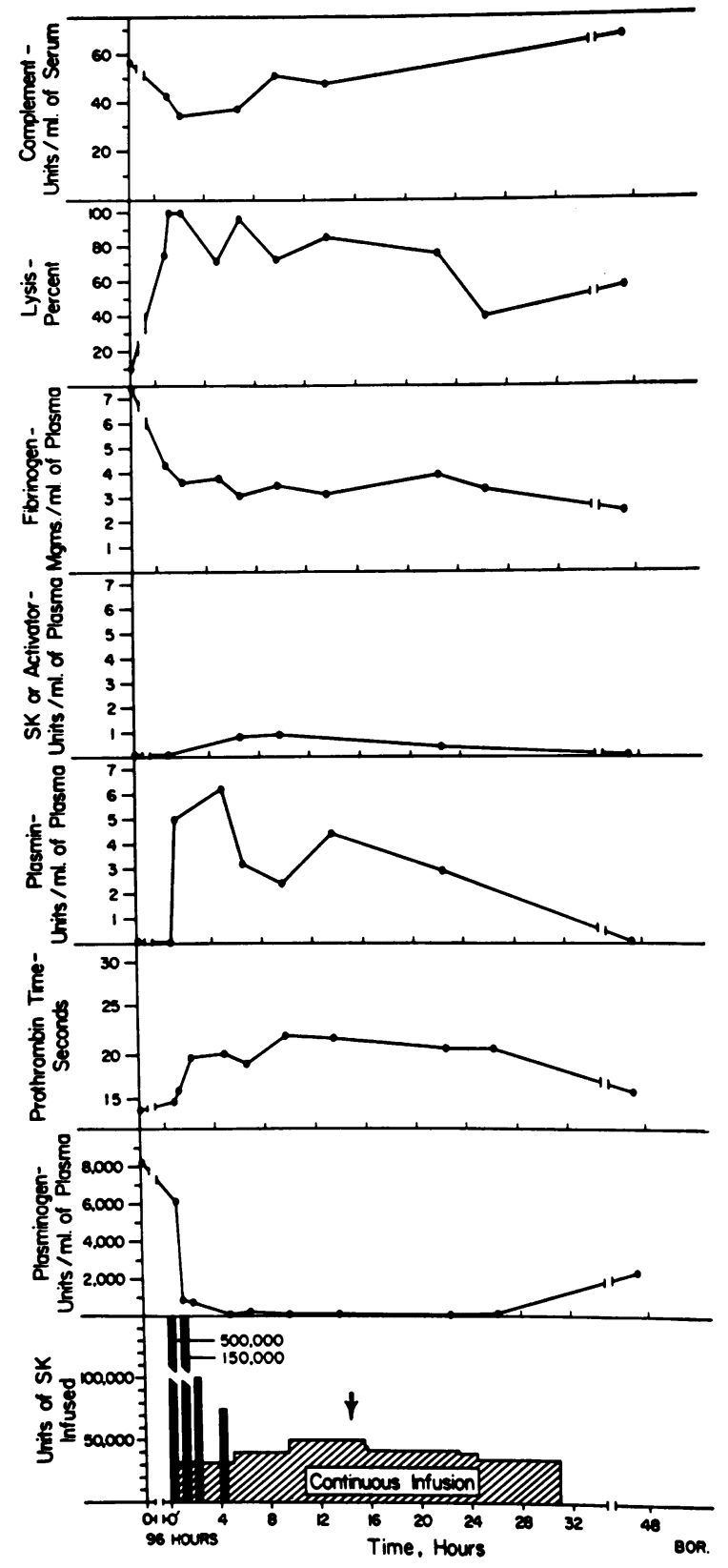

Fig. 5. Effect of Intravenous Infusion of 2,145,000 Units of Streptokinase in Patient BOR, Treated ACCORDING to METHOD $S K-P$ FOR 31 Hours

Ninety-six hours elapsed between the time preinjection samples were taken and the beginning of streptokinase infusion. Solid bars represent rapid injection of a major part of priming and first sustaining doses of SK.

minogen, plasmin, free SK, prothrombin time, fibrinogen and complement were maintained at relatively constant levels during Phase III. The only change was seen in the per cent lysis which 
went down progressively as the amount of free plasmin decreased during the infusion.

Clinical observations and X-ray venograms, made on Patient BOR the day following the infusion, revealed that both clots had lysed and did not recur.

\section{B. The lysis of artificially induced blood clots in vivo}

Standard blood clots, 5 to $20 \mathrm{~cm}$. long, were artificially induced in the large superficial veins of the forearm or the superficial saphenous veins of volunteers as described in the section on $\mathrm{Ma}$ terials and Methods. Thirty-two clots were induced in 26 patients by a "closed" technique utilizing a dental broach.

Three untreated control clots produced by the morrhuate technique and 10 by the dental broach technique went on to eventual fibrosis. None spontaneously lysed within three or more weeks of observation. Five were excised three to five weeks after they were formed and gross and histological section showed them to be fibrosed.

In six patients, two clots were induced, one 48 hours and one 24 hours, respectively, prior to the SK infusion.

The total dose and duration of each of the SK infusions in the patients treated according to Methods $P, S K$ and $S K-P$ are summarized in Table III.

In those patients treated by Method $P$ the total amount of SK infused averaged about 85,000 units and ranged from 50,000 to 150,000 units (Table III). Since intermittent, small doses of SK sufficed to maintain a fibrinolytic system in these patients for long periods of time, the duration of the infusion was comparatively short, averaging only six hours. Patients with low antibody and inhibitor were generally selected for this, since a relatively "pure" plasmin system could be readily maintained in this type of patient over a 24 hour period with only 25,000 to 50,000 units of SK.

An exception to this occurred with one patient in this group (Table III) who had a streptococcal infection for about two weeks prior to the infusion of SK. His circulating antibody and inhibitor at the time he volunteered for the study were within normal limits. However, his immune response increased rapidly after the infusion was started, presumably because of a "booster" response. Consequently, the infused SK was rapidly neutralized, only a very small amount remaining for the production of plasmin. In spite of receiving a total dose of $3,680,000$ units in 26 hours, his plasminogen level never went below 2,000 units from his normal of 5,200 units. Insufficient SK was available to overcome the immune response at this time.

The total amount of SK given to the patients, treated according to Methods $S K$ and $S K-P$, averaged $1,928,500$ and $1,466,125$ units, and the mean duration of the infusions was 29 and 26.5 hours, respectively (Table III).

The X-rays in Figures 6 and 7 illustrate the course of a typical patient treated according to Method SK-P. A thrombus was induced in the patient's right arm 48 hours prior to the infusion and in the patient's left arm 24 hours prior to the infusion. Venograms made on the right arm (Figure 6b) and on the left arm (Figure $7 \mathrm{~b}$ ), immediately prior to the infusion, showed that the previously patent vessels were completely occluded. The 48 hour clot (Figure 6b) was esti-

TABLE III

Total dose and duration of the $S K$ infusion in patients treated according to Methods $P, S K$ and $S K-P$

\begin{tabular}{|c|c|c|c|c|c|}
\hline Method & $\begin{array}{l}\text { No. in } \\
\text { group }\end{array}$ & $\begin{array}{l}\text { Total dose } \\
\text { of SK } \\
\text { (average) }\end{array}$ & $\begin{array}{c}\text { Total dose of SK } \\
\text { (range) }\end{array}$ & $\begin{array}{c}\text { Duration of } \\
\text { infusion } \\
\text { (average) }\end{array}$ & $\begin{array}{c}\text { Duration of } \\
\text { infusion } \\
\text { (range) }\end{array}$ \\
\hline $\begin{array}{l}\text { P } \\
\text { SK } \\
\text { SK-P }\end{array}$ & $\begin{array}{l}5^{*} \\
5 \\
8\end{array}$ & $\begin{array}{c}\text { units } \\
85,000^{*} \\
1,928,500 \\
1,466,125\end{array}$ & $\begin{array}{c}\text { units } \\
50,000-150,000^{*} \\
1,050,000-2,764,000 \\
715,000-2,145,000\end{array}$ & $\begin{array}{l}\text { hrs. } \\
6^{*} \\
29 \\
26.5\end{array}$ & $\begin{array}{l}h r s . \\
3-9 \\
21-40 \\
7-48\end{array}$ \\
\hline
\end{tabular}

* One patient, who fulfilled the biochemical requirements for inclusion in this group, with an excess of SK-plasmin, was omitted from this tabulation. This patient had a streptococcal infection for about two weeks prior to the infusion and a rapidly rising titer of SK antibody after the infusion was started. He received a total dose of 3,680,000 units of SK over a period of 26 hours. 
mated to be $20 \mathrm{~cm}$. long and the 24 hour clot (Figure $7 \mathrm{~b}$ ) about $15 \mathrm{~cm}$. long, by both clinical and radiological criteria. SK was infused over a period of 36 hours by Method SK-P (1,805,500 units). The 24 hour clot lysed completely in 18 hours, but the 48 hour clot did not lyse until nearly 30 hours. The infusion was continued for an additional six hours to prevent reformation of the clot. X-ray venograms made the following morning confirmed the fact that clot lysis had occurred (Figures $6 \mathrm{c}$ and $7 \mathrm{c}$ ). These clots did not reform.

\section{Relative effectiveness of Methods $P, S K$ and $S K-P$}

Table IV summarizes a number of the experiments.

In seven instances, SK was infused according to the method which produced circulating plasmin (Method $P$ ) without detectable free SK. Partial lysis of the clots occurred in three and complete lysis in one, but all four clots reformed. Thus, no persistent clot lysis occurred.

SK was infused in seven instances according to the method which produced circulating free SK (Method SK) without demonstrable amounts of plasmin. Two clots lysed and did not reform, but complete or incomplete lysis was followed by reformation of the clot in three. No lysis was evident in two clots. Persistent clot lysis occurred in only two of seven clots treated by this method.

SK was infused in 11 instances according to the method which produced small amounts of circulating free SK and plasmin (Method SK-P). Complete, persistent clot lysis occurred in all. It is evident that consistent and reproducible results were obtained with Method $S K-P$ only.

In no instance did persistent thrombolysis of 48 hour clots occur unless Method SK-P was used.

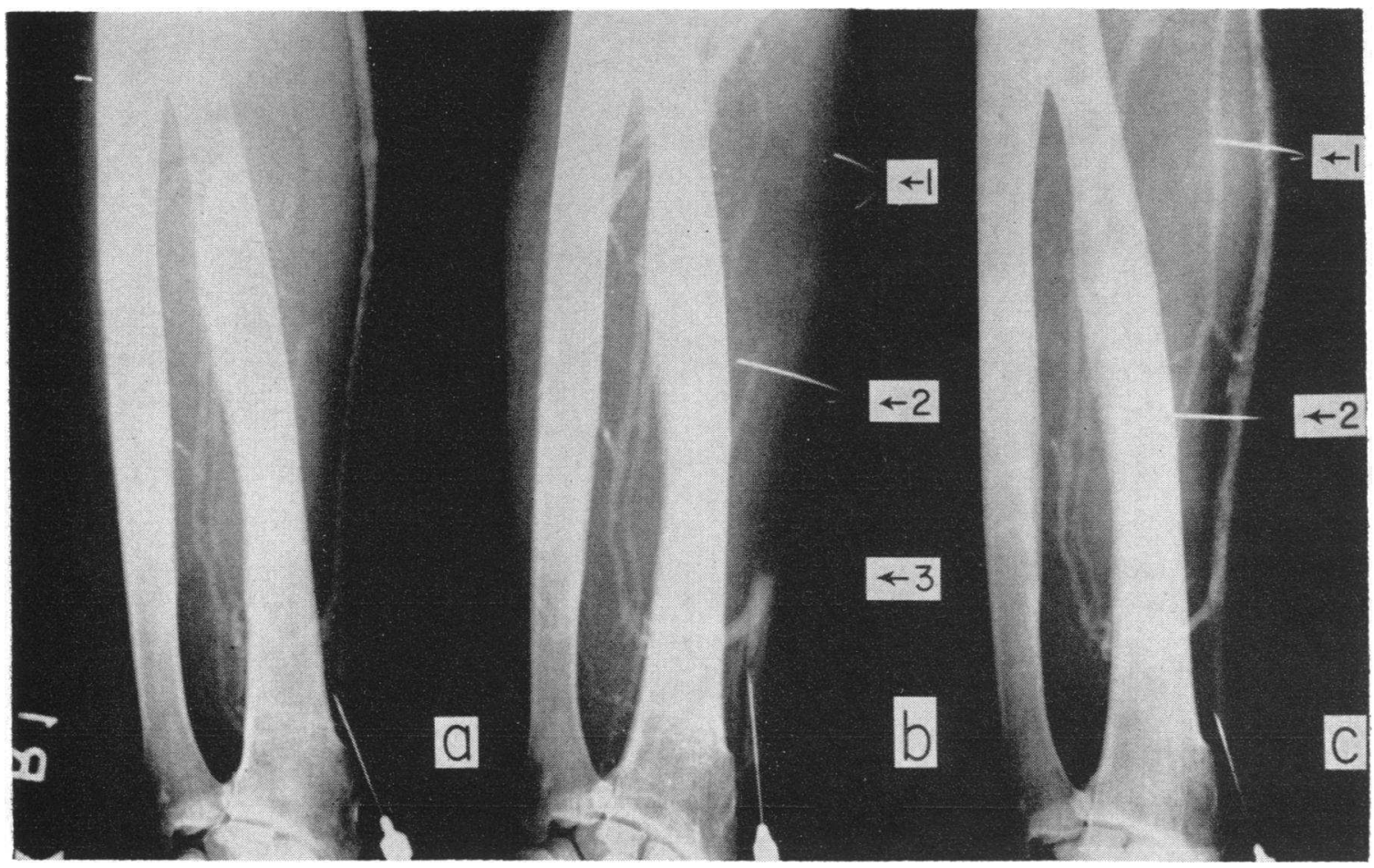

Fig. 6. X-Ray Demonstration of Clot Lysis

To determine extent of clot lysis and reformation, venograms were made on Patient G's right arm: $a$ ) prior to induction of clot, as a control ; $b$ ) 48 hours after clot was induced and prior to infusion of SK, defining the clot; and c) 24 hours after the SK infusion, showing that complete lysis had occurred, without clot reformation. Radiopaque lines at 1 and 2 were made by nichrome wires on skin surface to define original area of clot induction. Arrow at 3 indicates distal portion of the clot. Patient was treated according to Method $S K-P$, utilizing small amounts of plasmin and free SK. Lysis of the clot occurred after 30 hours of infusion. 


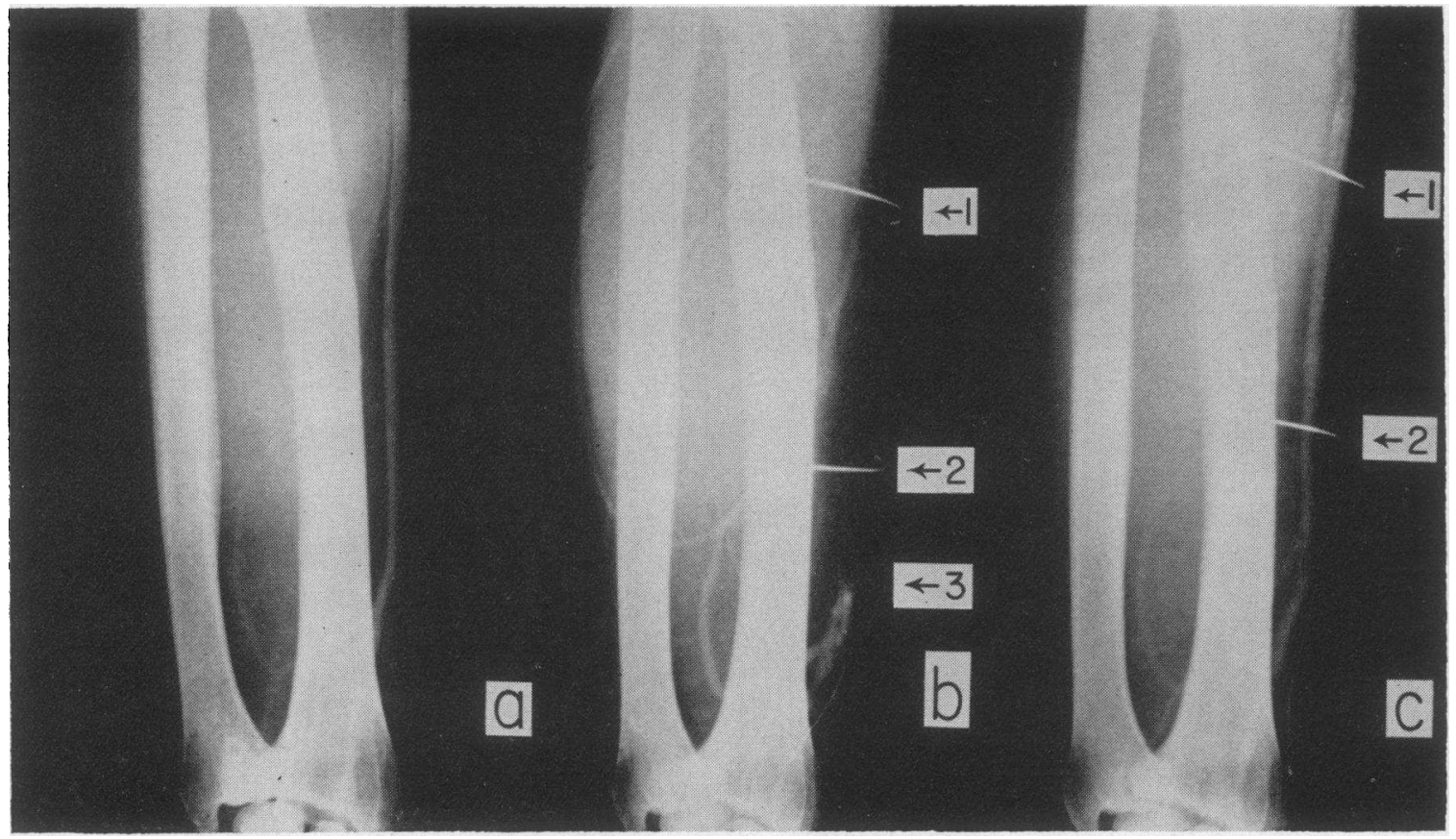

Fig. 7. X-Ray Demonstration of Clot Lysis

To determine extent of clot lysis and reformation, venograms were made on Patient G's left arm: $a$ ) prior to the induction of clot, as a control ; b) 24 hours after clot was induced and prior to infusion of SK, defining the clot; and c) 24 hours after SK infusion, showing that complete lysis had occurred, without clot reformation. Radiopaque lines at 1 and 2 were made by nichrome wires on skin surface to define original area of clot induction. Arrow at 3 indicates distal portion of the clot. Patient was treated according to Method $S K-P$, utilizing small amounts of plasmin and free SK. Lysis of clot occurred after 18 hours of infusion.

It was our impression that 48 hour clots took longer and were more difficult to lyse than 24 hour clots.

\section{Toxicity}

Toxicity studies on SK have been published previously $(27,31)$. In the course of the present study high purity streptokinase (600 units per $\mu \mathrm{g}$. of $\mathrm{N}$ ) was used exclusively. No hypo- tension was evident in any of the patients studied. An occasional rise in temperature, to $102^{\circ} \mathrm{F}$., was immediately controlled by giving the patient amidopyrine and chlorprophenpyramine maleate as described in Materials and Methods. In one instance, the patient's temperature rose to $103^{\circ} \mathrm{F}$.

There has been no evidence of embolic phenomena.

The patients treated by Method $P$ presented a

TABLE IV

Lysis of intravascular blood clots in man by the intravenous infusion of streptokinase

\begin{tabular}{|c|c|c|c|c|c|c|c|c|c|c|}
\hline \multirow[b]{2}{*}{$\begin{array}{c}\text { Method of } \\
\text { therapy }\end{array}$} & \multirow[b]{2}{*}{$\begin{array}{l}\text { No. of } \\
\text { clots }\end{array}$} & \multicolumn{2}{|c|}{$\begin{array}{l}\text { Age of clot before } \\
\text { infusion }\end{array}$} & \multirow[b]{2}{*}{$\because$} & \multicolumn{5}{|c|}{ Clot lysis effected } & \multirow[b]{2}{*}{$\begin{array}{l}\text { No lysis } \\
\text { effected }\end{array}$} \\
\hline & & 24 hrs. & $48 \mathrm{hrs}$. & & Partial & Complete & $\begin{array}{c}\text { Clot } \\
\text { reformed }\end{array}$ & $\begin{array}{c}\text { Lysis } \\
\text { persisted }\end{array}$ & Total & \\
\hline $\mathrm{P}$ & 7 & 6 & 1 & & 3 & 1 & \multirow{3}{*}{$\begin{array}{c}4 \\
3 \\
3 \\
(1-48 \mathrm{hrs} .) \\
0\end{array}$} & 0 & 4 & \multirow{3}{*}{$\begin{array}{c}3 \\
(1-48 \mathrm{hrs} .) \\
2 \\
(2-48 \mathrm{hrs} . \\
0\end{array}$} \\
\hline SK & 7 & 4 & 3 & & 3 & 2 & & 2 & 5 & \\
\hline SK-P & 11 & 8 & 3 & & 0 & 11 & & 11 & $\begin{array}{c}11 \\
(3-48 \text { hrs. })\end{array}$ & \\
\hline Total & 25 & 18 & 7 & & 6 & 14 & 7 & 13 & 20 & 5 \\
\hline
\end{tabular}


potential hazard when plasmin was in great excess and the fibrinogen, prothrombin and accelerator globulin were severely depleted. Mild ecchymosis and petechiae formed in the skin of two of these patients.

The patients treated by Methods $S K$ and $S K-P$ formed little plasmin when SK was injected rapidly in Phase II and were remarkably well controlled in this respect. The prothrombin time remained under 26 seconds and rarely went higher than 24 seconds. No ACTH or cortisone has been used, or found to be necessary in these patients; an observation in contrast to the findings of other workers (16).

One severely hypertensive volunteer had a previous history of bouts of hypertensive encephalopathy with flaccid upper and lower extremities on the left lasting for several days. A single 24 hour clot was induced. At the end of his SK infusion, according to Method $S K-P$, the dose of SK was decreased, his prothrombin time returned to normal, the per cent lysis was within normal limits, and no plasmin or activator was found in the circulating blood. After the infusion, he developed a severe hypertensive encephalopathy similar to the previous episodes, but this time his neurological signs gradually progressed. Two days later he died. On autopsy, a firm blood clot was found around the lenticulostriate artery with no evidence of clot lysis. Microscopic section showed a rupture of the lenticulostriate artery. Thus, although a break occurred in the vessel wall, there is no evidence to suggest that this system affects the continuity of the blood vessels. Since there was no fibrinolysis in the peripheral blood of this patient at the onset of the encephalopathy, and no fibrinolysis in the clot adjacent to the lenticulostriate artery at autopsy, this patient's death was thought to have no relation to the previously induced fibrinolytic system. Indeed, a controlled fibrinolytic system has been induced over 150 times in patients in this hospital without serious toxicity.

On the other hand, the case history presented here emphasizes the need for great care in the selection of patients, with special reference to a possible or potential break in the continuity of the vascular endothelium.

\section{DISCUSSION}

The present study has demonstrated for the first time, so far as the writers are aware: $a$ ) that consistent and reproducible intravascular clot lysis can be produced in man; $b$ ) that this may be produced by activating the naturally occurring fibrinolytic enzyme of human plasma with SK; and $c$ ) that this same system may be used to prevent reformation of the clots.

Although the observations reported here are limited in number, they acquire broader significance from previous studies in animals conducted in this and other laboratories, where it was shown that fibrinolysis could be produced by an excess of activator or SK without excessive plasmin formation $(19,29,32)$. In vitro studies by Ratnoff (33), Müllertz (34) and Alkjaersig, Fletcher and Sherry (35) indicate that fibrinolysis is produced more readily by activator or SK than by plasmin alone.

Since clot lysis has been produced in animals with trypsin (29) and preformed plasmin (14, 36 ), it was desirable to compare the relative efficacy of a fibrinolytic system utilizing excess plasmin with a fibrinolytic system utilizing an excess of free SK or activator, under comparable conditions, in man.

The data show that in vivo clot lysis occurred when an excess of free SK or activator was produced (Methods $S K$ and $S K-P$ ), but did not occur when plasmin was in excess $(\operatorname{Method} P)$. Thus effective clot lysis is presumed to be due to free SK or activator. Since the assay used did not differentiate the two, and because human plasminogen is thought to contain the precursors for both activator and plasmin $(7,8)$, clot lysis could result from the combination of adsorbed plasminogen and 1) circulating free SK or 2) activator, or 3) both.

The relatively high levels of plasminogen which are present with Method $P$ militates against the formation of free SK with this system, but is entirely consistent with the formation of activator. The large amount of plasmin that is produced also indicates that plasminogen has been activated. However, it is not certain that activator is stable at these low concentrations of SK. Therefore, the fact that little or no clot lysis occurred when Method $P$ was used, may be due to the qualitative 
inefficacy of plasmin and activator as fibrinolytic agents, or a quantitative insufficiency of free SK and activator.

The very low levels of plasminogen available for activator formation with Methods $S K$ and $S K-P$, which appear to be necessary for effective clot lysis in vivo, suggest that fibrin lysis was caused by free SK in excess of that which combined with plasminogen to form activator and plasmin in the circulating blood. Although the available evidence favors free SK, it is entirely circumstantial in nature.

In preliminary experiments, reformation of clots induced by intimal irritation usually took place immediately after clot lysis had occurred and the infusion was discontinued, indicating that intimal repair was probably necessary to prevent reformation of the clot.

Since clot reformation had been prevented in animals (19) by prolonging the infusion of SK, it was decided to use the SK-plasmin system as 1) a fibrinolytic agent and 2) an anticoagulant.

In Method $P$, the excess plasmin depleted the accelerator globulin and prothrombin, thereby acting as an anticoagulant. Unfortunately, thrombolysis was inadequate in patients treated by this method.

When an excess of free SK was produced (Method SK), little plasmin was formed, the prothrombin time remained under 25 seconds and anticoagulant action was limited. Therefore, the plasminogen on the clot and free SK in the blood were utilized to produce continuous fibrin lysis, the clot constantly reforming and lysing until intimal repair was effected. This was only partially successful in that most of the clots lysed, but most of them also reformed in patients treated by this method. It was concluded that the initial lysis of the clot had occurred because plasminogen had been adsorbed on the clot when it formed (prior to the infusion). As soon as the circulating plasminogen decreased to less than 100 units, adsorption of plasminogen on the reforming clot became limited and further lysis was prevented.

In Method $S K-P$, the amount of free SK and plasmin produced were small, but the plasminogen level was maintained at 100 to 200 units until persistent clot lysis occurred. There was little evidence of clot reformation because lysis of the clot probably occurred simultaneously, in dynamic equilibrium with clot reformation. Intimal repair was completed by prolonging the infusion of SK four to six hours after clot lysis became evident, clinically.

The following hypothesis was formulated on the basis of the studies previously mentioned (19, $29,32,35)$ and the data presented here:

Circulating plasminogen is adsorbed on the fibrin clot as it forms. Adsorption effectively removes the plasminogen from association with, and the effect of, circulating inhibitors of both plasmin and activator. SK is infused in amounts calculated to neutralize the circulating antibody and fast-acting inhibitors. Additional infused SK, circulating free in the blood stream, combines specifically with its substrate plasminogen which had been previously adsorbed on the clot. Fibrinolysis is produced.

The intimal damage to the vein wall persists. Clot reformation tends to occur. As the fibrin clot reforms, it adsorbs all the constituents essential for its own destruction: plasminogen, SK and plasmin. Consequently, fibrinolysis recurs. This sequence of events is thought to continue until intimal repair is effected, preventing further reformation of the clot.

Thus it is concluded that a fibrinolytic system with an excess of free SK or activator (Methods $S K$ or $S K-P$ ) will consistently produce clot lysis and will be an effective therapeutic tool if it is modified to prevent clot reformation as well (Method SK-P).

Studies are now in progress to determine whether anticoagulants such as heparin can be used in man as ancillary agents in the anticoagulant phase of clot lysis. Previous experiments in animals indicated they could, when given for 24 hours or more (19).

The experimental data presented here, although limited, strongly suggest that 48 hour clots are initially more difficult to lyse and reform more rapidly than 24 hour clots, and are therefore in basic agreement with the studies of Back, Ambrus, Simpson and Shulman (37).

Toxicity due to streptokinase has been markedly decreased since high purity SK became available. Thus, hypotension following its administration has virtually disappeared and pyrogenicity is readily controlled by antipyretic agents. There is, however, the possibility of serious extravascular hemorrhage from vascular dysfunction or trauma during the SK infusion, despite the fact that the coagulation system is not seriously depleted when the patient is treated according to Method $S K-P$. 
Although the therapeutic potential of intravenous SK or plasmin remains to be explored on a much wider basis (13-16), the results presented here clearly indicate that the fundamental assumptions implicit in the therapeutic application of intravenous SK or SK-plasmin are correct. SK will consistently lyse clots and prevent reformation of the clots when infused intravenously under carefully controlled biochemical conditions. The critical nature of these conditions, however, requires simpler methods for the evaluation of the fibrinolytic system and an approach to the technique of infusion which will create these conditions in any individual by the simultaneous administration of one or more agents to lyse a clot, prevent it from reforming, and diminish the potential hazard from systemic fibrinolysis.

\section{SUMMARY}

1. Large amounts of high purity streptokinase (SK) have been infused intravenously to produce intravascular clot lysis in man under sharply defined conditions.

2. Thirty-eight blood clots, 5 to $20 \mathrm{~cm}$. long, were induced in the peripheral veins of volunteers by direct irritation of the intima with a dental broach or by chemical irritation with sodium morrhuate. No spontaneous lysis occurred in 13 controls. The position and size of the clots were documented clinically and by venograms. In the experimental group, SK was infused intravenously into a contralateral extremity 24 or 48 hours after production of the clot.

3. Three methods have been developed and tested for their fibrinolytic potential in vivo. The methods produced:

$A)$ large amounts of circulating plasmin (Method $P$ );

$B)$ large amounts of free $\mathrm{SK}$ or activator (Method SK) ;

$C)$ small amounts of plasmin and free $\mathrm{SK}$ or activator (Method $S K-P$ ).

In Method $P$, a priming dose of SK is calculated from the quantitative determination of the antibody and inhibitor in each patient's circulating blood to neutralize his antibody and inhibitor. Additional infused SK is free to produce an active fibrinolytic system. Small, intermittent doses of
SK, 25,000 to 50,000 units per day, suffice to produce large amounts of plasmin.

SK was infused in seven instances according to Method $P$. There was no persistent clot lysis. Although minimal lysis was present in three and complete lysis occurred in one, all the clots reformed. Circulating plasmin was present in all seven without detectable free SK.

In Method SK, the priming dose of SK neutralizes the patient's circulating antibody and inhibitor as in Method $P$. The infusion of a first sustaining dose of 100,000 to 300,000 units of SK in one to three hours usually serves to reduce the plasminogen sharply and protect the patient by preventing the production of excessive amounts of plasmin. The continuous infusion of 45,000 to 65,000 units per hour provides large amounts of free SK or activator. When SK was infused in seven instances, according to Method $S K$, two clots lysed without reforming. Incomplete or complete lysis was followed by clot reformation in three (presumably due to a deficiency of circulating plasminogen). No lysis occurred in two.

In Method $S K-P$, the priming dose and first sustaining dose of SK are infused as in Method $S K$ above. The second sustaining dose of $\mathrm{SK}$ is infused at 25,000 to 45,000 units per hour to provide plasmin and free SK (or activator) without excessive depletion of plasminogen. For this reason, the rate of infusion for Method $S K-P$ is necessarily very critical. Frequent determinations of the patient's plasminogen, plasmin, free SK, plasmin-activator and prothrombin time assisted in maintaining this critical infusion rate.

In 11 instances SK was infused according to Method SK-P. Persistent clot lysis was obtained in all 11.

4. Forty-eight hour clots were more resistant to lysis than 24 hour clots regardless of the method used.

5. No embolic complications have been observed.

\section{CONCLUSIONS}

The results demonstrate that SK will consistently and reproducibly lyse intravascular clots and prevent reformation of the clots when infused intravenously into patients under precisely defined biochemical conditions. 


\section{ACKNOWLEDGMENTS}

The authors wish to acknowledge the capable technical assistance of Mr. Jack Newman, Miss Anne Ong, Miss Lillian Gong and Miss Frieda Steinschneider.

\section{REFERENCES}

1. Tillett, W. S., and Sherry, S. The effect in patients of streptococcal fibrinolysin (streptokinase) and streptococcal desoxyribonuclease on fibrinous, purulent and sanguinous pleural exudations. J. clin. Invest. 1949, 28, 173.

2. Tillett, W. S., Sherry, S., Christensen, L. R., Johnson, A. J., and Hazelhurst, G. Streptococcal enzymatic debridement. Ann. Surg. 1950, 131, 12.

3. Tillett, W. S. Studies on the enzymatic lysis of fibrin and inflammatory exudates by products of hemolytic streptococci. Harvey Lectures 1949-1950, 45, 149.

4. Geiger, W. B. Involvement of a complement-like factor in the activation of blood protease. J. Immunol. 1952, 69, 597.

5. Müllertz, S., and Lassen, M. An activator system in blood indispensable for formation of plasmin by streptokinase. Proc. Soc. exp. Biol. (N. Y.) 1953, 82, 264.

6. Sherry, S. The fibrinolytic activity of streptokinase activated human plasmin. J. clin. Invest. 1954, 33, 1054.

7. Kline, D. L., and Fishman, J. B. Plasmin: The humoral protease. Ann. N. Y. Acad. Sci. 1957, 68, 25.

8. Alkjaersig, N., Fletcher, A. P., and Sherry, S. The activation of human plasminogen. II. A kinetic study of activation with trypsin, urokinase, and streptokinase. J. biol. Chem. 1958, 233, 86.

9. Tillett, W. S., Edwards, L. B., and Garner, R. L. Fibrinolytic activity of hemolytic streptococci. The development of resistance to fibrinolysis following acute hemolytic streptococcus infections. J. clin. Invest. 1934, 13, 47.

10. Jacobsson, K. I. Studies on the determination of fibrinogen in human blood plasma. II. Studies on the trypsin and plasmin inhibitors in human blood serum. Scand. J. clin. Lab. Invest. 1955, Suppl. 14, $7,3$.

11. Norman, P. S., and Hill, B. M. Studies on the plasmin system. III. Physical properties of the two plasmin inhibitors in plasma. J. exp. Med. 1958, 108, 639.

12. Johnson, A. J., McCarty, W. R., and Tillett, W. S. In preparation.

13. Sherry, S., and Alkjaersig, N. Biochemical, experimental, and clinical studies of proteolytic enzymes: With particular reference to the fibrinolytic enzyme of human plasma. Ann. N. Y. Acad. Sci. 1957, 68, 52 .
14. Ambrus, J. L., Ambrus, C. M., Back, N., Sokal, J. E., and Collins, G. L. Clinical and experimental studies on fibrinolytic enzymes. Ann. N. Y. Acad. Sci. 1957, 68, 97.

15. Cliffton, E. E. The use of plasmin in humans. Ann. N. Y. Acad. Sci. 1957, 68, 209.

16. Fletcher, A. P., Alkjaersig, N., Smyrniotis, F. E., and Sherry, S. The treatment of patients suffering from early myocardial infarction with massive and prolonged streptokinase therapy. Trans. Ass. Amer. Phycns 1958, 71, 287.

17. Gordon, S., and Ablondi, F. B. The effect of streptococcal enzymes and other agents on experimental inflammation. Ann. N. Y. Acad. Sci. 1957, 68, 89.

18. Miller, J. M., Surmonte, J. A., Ginsberg, M., and Ablondi, F. B. Clinical experience with the injection of streptokinase intramuscularly in the treatment of infection and edema. Maryland med. J. 1955, 4, 188.

19. Johnson, A. J., and Tillett, W. S. The lysis in rabbits of intravascular blood clots by the streptococcal fibrinolytic system (streptokinase). J. exp. Med. 1952, 95, 449.

20. Tillett, W. S., Johnson, A. J., and McCarty, W. R. The intravenous infusion of the streptococcal fibrinolytic principle (streptokinase) into patients. J. clin. Invest. 1955, 34, 169.

21. Christensen, L. R. Methods for measuring the activity of components of the streptococcal fibrinolytic system, and streptococcal desoxyribonuclease. J. clin. Invest. 1949, 28, 163.

22. Laki, K. The polymerization of proteins: The action of thrombin on fibrinogen. Arch. Biochem. 1951, 32, 317.

23. Schwert, G. W., and Takenaka, Y. A spectrophotometric determination of trypsin and chymotrypsin. Biochim. biophys. Acta 1955, 16, 570.

24. Blömback, B., and Blömback, M. Purification of human and bovine fibrinogen. Ark. Kemi 1956, 10, 415.

25. Fischel, E. E., Pauli, R. H., and Lesh, J. Serological studies in rheumatic fever. II. Serum complement in the rheumatic state. J. clin. Invest. 1949, 28, 1172.

26. Singher, H. O. Personal communication.

27. Johnson, A. J., Fletcher, A. P., McCarty, W. R., and Tillett, W. S. The intravascular use of streptokinase. Ann. N. Y. Acad. Sci. 1957, 68, 201.

28. Ferguson, J. H., quoted by Flynn, J. E., and Standley, E. T. On the conversion of prothrombin to thrombin in Transactions of the Second Conference on Blood Clotting and Allied Problems, J. E. Flynn, Ed. Josiah Macy, Jr., Foundation, New York, 1949, p. 174.

29. Sherry, S., Titchener, A., Gottesman, L., Wasserman, $P$., and Troll, W. The enzymatic dissolution of experimental arterial thrombi in the dog by trypsin, chymotrypsin and plasminogen activators. J. clin. Invest. 1954, 33, 1303. 
30. Pillemer, L., Ratnoff, O. D., Blum, L., and Lepow, I. H. The inactivation of complement and its components by plasmin. J. exp. Med. 1953, 97, 573.

31. Johnson, A. J., Fletcher, A. P., McCarty, W. R., and Tillett, W. S. Effects in patients of intravenous infusions of purified streptokinase preparations. Proc. Soc. exp. Biol. (N. Y.) 1957, 94, 254.

32. Sherry, S., Callaway, D. W., and Freiberg, R. Prevention of postoperative adhesions in the dog by intravenous injections of plasminogen activators. Proc. Soc. exp. Biol. (N. Y.) 1955, 90, 1.

33. Ratnoff, O. D. Studies on a proteolytic enzyme in human plasma. IX. Fibrinogen and fibrin as substrates for the proteolytic enzyme of plasma. J. clin. Invest. 1953, 32, 473.
34. Müllertz, S. The action of plasmin on fibrin and fibrinogen in blood. Acta physiol. scand. 1953, 28 , 29.

35. Alkjaersig, N., Fletcher, A. P. and Sherry, S. Mechanism of clot lysis by plasmin (abstract). Fed. Proc. 1958, 17, 2.

36. Cliffton, E. E., Grossi, C. E., and Cannamela, D. Lysis of thrombi produced by sodium morrhuate in the femoral vein of dogs by human plasmin (fibrinolysin). Ann. Surg. 1954, 139, 52.

37. Back, N., Ambrus, J. L., Simpson, C. L., and Shulman, S. Study on the effect of streptokinase-activated plasmin (fibrinolysin) on clots in various stages of organization. J. clin. Invest. 1958, 37, 864. 